\title{
EDITORIALS
}

\section{Guidelines and Comments to Authors (and Readers)}

The subject matter of the Irish Journal of Psychological Medicine is psychiatry, neuropsychiatry, psychosomatic medicine, and psychological medicine; together with the related biological, psychological and social sciences. The Journal welcomes contributions on the psychological aspects of any branch of medicine or surgery; and contributions from the various subspeciality areas, eg forensic psychiatry, child psychiatry, psychogeriatrics, mental handicap, addictions, community psychiatry/epidemiology, psychopharmacology, psychometrics and psychotherapies. The Journal will accept original articles, clinical reports, review articles, perspective articles, historical pieces, letters to the Editor and book reviews.

Manuscripts will be accepted when prepared in accordance with the International Committee of Medical Journal Editors. ${ }^{1}$ The International Committee has addressed not only stylistic requirements, but substantive issues which are relevant to written content and even to protocol design. These include a new section on statistical guidelines, which has been further amplified and explained by Bailar and Mosteller. ${ }^{2}$ To ensure that these standards are approached, or limitations recognised, it is advisable, in addition to using standard statistical texts ${ }^{3}$ or computer programmes ${ }^{4}$, to consult with a medical or psychological statistician.

The uniform stylistic requirements of the International Committee are not simply minor irritants for authors, but ensure that their contributions will come to international scientific attention. Manuscripts should begin with an Abstract of no more than 150 words, followed by a list of 3-10 Key Words or short phrases drawn, if possible, from the medical subject headings (MeSH) list of Index Medicus. Journal references should be in the "Vancouver" as opposed to the "Harvard" style. The Vancouver style is illustrated by the four references below: the first two illustrate the style of reference to an article $e^{1,2}$, with titles of journals abbreviated as in Index Medicus: the third and fourth illustrate the style of reference to a book ${ }^{3}$ and to an agency publication ${ }^{4}$. Further details and examples of reference style are listed by the International Committee ${ }^{1}$.

All materials sent to the Journal for publication should be accompanied by a covering letter signed by all the authors, and such material will become the property of the Journal until, and if, application for publication is refused. Material so referred should not be sent elsewhere for publication. One copy of the manuscript should be retained by the author(s) for reference, and four copies, one of these being the original, should be sent to the Editor, Irish Journal of Psychological Medicine, St Brendan's Hospital, PO Box 418, Rathdown Road, Dublin 7, Ireland.

All contributions are peer-reviewed by at least two assessors, and where relevant, by a statistical assessor. Where revisions are sought prior to publication, the assessments will be sent, unexpurgated (but anonymous) to the corresponding author. Apart from stylistic requirements, authors are advised to make only those revisions which they agree will improve their manuscript. Authors should reply to the Editor in detail concerning those suggestions which they disagree with, or are unable to incorporate into their revision. The Editor retains the final decision, including priority and time of publication, and the right to style and if necessary shorten material for publication.

Originality is sometimes more difficult to define in psychotherapy than in the "harder", more scientific aspects of psychiatry. Often it consists in a new way of saying old things, an unusual synthesis, or putting matters in a topical context. I found the brief clinical report ( $p$ 47) of a few fragments from the supervision of a recently revived community meeting in a dying hospital to be poignant and evocative. ("Hawthorn....is actually scheduled for closure... The staff [my emphasis] of the ward recently revived the practice of a daily community meeting and they asked me for supervision").

The John Dunne Medal is awarded annually by the Irish Journal of Psychological Medicine to a trainee from Ireland, Northern Ireland, or Great Britain. Dr John Dunne was the first Psychiatry Professor in Ireland and the President in 1955 of the Royal Medico-Psychological Association. This bronze medal is awarded to a trainee who has contributed substantially to an original article or brief report published by the Journal in the previous year.

Such research need not be earth-shattering in its implications or exceptionally high-powered in its conception (though not trivial either). Where a thoughtful question or hypothesis has arisen from clinical work, (as in the study on p 35 of predicting nonattenders to a psychosexual clinic from the referral letter), and the research is well designed and executed to answer the question or test the hypothesis, such research is eminently valid for publi- 
cation, even when the results are mainly negative. The scientific literature is biased by the relative paucity of reports of research studies with negative results, especially when financial and political backing and numbers of subjects were modest, though adequate. Such studies may stimulate others to greater thoughts and actions.

Mark Hartman, MRC Psych, Consultant Psychiatrist, Editor.

\section{References}

1. International Committee of Medical Joumal Editors. Uniform requirements for manuscripts submitted to biomedical joumals. $\mathrm{Br}$ Med J 1988: 296: 401-5

2. Bailar JC, Mosteller F. Guidelines for Statistical Reporting in Articles for Medical Joumals. Ann Intem Med 1988; 108: 266-273

3. Bourke GJ, Daly LE, McGilvray J. Interpretation and Uses of Medical Statistics. 3rd ed. Oxford: Blackwell Scientific Publications, 1985: $315-319$

4. SAS Institute Inc. SAS User's Guide: Basics. Version 5 ed. Cary NC: 1985

\title{
Leadership in Health: Patient Satisfaction, Security for Professionals
}

\author{
Professor R J McClelland, F.R.C.Psych., M.D. Ph.D, D.I.C. Department of Mental Health, Queen's University, Belfast
}

In his Maudsley bequest lecture of 1978 Sir Dennis Hill, a stalwart in postgraduate medical education, concluded that despite all the difficulties which afflict our subject at the present time a career in psychiatry can still be one of the most rewarding in the whole of medicine. In his lecture he sought to outline the qualities of a good psychiatrist and from which 4 dimensions can be identified: Physician, Psychotherapist, Scientist, Leader ${ }^{1}$. It is perhaps the last which has been most neglected in medical education, undergraduate and postgraduate alike. Indeed for psychiatry there is a certain ambivalence about the concept of psychiatrist as leader. As Dr James Birley has commented "There are certain risks in regarding the Psychiatrist as leader. It smacks of a return of the Medical Superintendent". But such authoritarian images fail to recognise the positive aspects of leadership and the need for medical leadership. As Birley also notes "to ignore the importance of the most highly paid and highly trained member of the clinical team is equally dangerous. So in addition to clinical skills, our psychiatrist would have to become more sophisticated about the problems of management not only in the organisation of others but in the way he sees himself in the organisation"2. Birley anticipated by more than a decade Sir Roy Griffith's report on the management difficulties of the NHS where he described doctors as "natural managers" who must accept the management responsibilities which go with clinical freedom ${ }^{3}$.

It is my impression that our specialty has been among the first to recognise the important role of the physician as leader or "manager with a small $m$ ". Several factors have contributed to this increased awareness. One is psychiatry's recognition of our dependency on other professionals and which has led to the team approach to clinical care and management. Second with the developments in community care and the loss of the structural security provided by an institutional base there are anxieties about our future role and our relationships with other professionals. Tomorrows psychiatrist can no longer assume the natural authority provided within the old psychiatric hospital.

It is the opinion of a growing number of medical educationalists and experienced practitioners that the effectiveness of health care delivery and its cost-effectiveness hinge increasingly on the effective leadership and responsible management executed by each and every consultant and each and every general practitioner. The recent GMC(UK) Education Committee Report now recognises the management responsibilities of all doctors in the Health Service. Their recommendations on the training of specialists includes "mastery of the skills required to work within a team and where appropriate assume the responsibilities of team leader"4. While there are special problems for leaders and leadership within the public sector in general and within the health service in particular, I believe we can learn a great deal from leadership training in the industrial sector. The emphasis laid on leadership skills in industry is reflected in the magnitude and number of such documents as the training prospectus of the Irish Management Institute, (150 pages) ${ }^{5}$. However, more humble documents such as "Doctors and Management Development" are now emerging from the NHS Training Authority which lay stress on the importance of management awareness and management training for medical graduates at all stages of training 6 .

One difficulty that is sometimes raised is the inappropriateness of the industrial model of leadership in situations where the doctor is the most skilled member of the team. Another argument against the applicability of the industrial model is that its product is usually inanimate while ours is people. However there are close parallels for example between a skilled surgeon and the pilot of a large aircraft. Both are the most skilled member of their respective teams. For both the common "product" is the safety and welfare of a group of people. Commercial airlines today pay particular attention to the leadership qualities and skills of their pilots. Leadership matters because people matter. 